\title{
Point defects and high temperature creep of NiO single crystals (*)
}

\author{
J. Cabrera-Cano \\ Departamento de Optica, Facultad de Ciencias, Universidad, Sevilla, Spain \\ and J. Castaing \\ Laboratoire de Physique des Matériaux, C.N.R.S.-Bellevue, 92190 Meudon, France
}

(Reçu le 6 novembre 1979, accepté le 10 janvier 1980)

\begin{abstract}
Résumé. - Des monocristaux de $\mathrm{NiO}$ ont été comprimés par fluage entre $1070{ }^{\circ} \mathrm{C}$ et $1550^{\circ} \mathrm{C}$ sous des contraintes comprises entre $10 \mathrm{MPa}$ et $150 \mathrm{MPa}$. La pression partielle d'oxygène varie entre $10^{-5} \mathrm{~atm}$. et l'air. Le fluage sta-

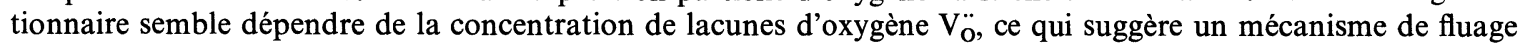
dépendant de la diffusion de l'oxygène.
\end{abstract}

\begin{abstract}
NiO single crystals have been crept in compression between $1070{ }^{\circ} \mathrm{C}$ and $1550{ }^{\circ} \mathrm{C}$ for stresses in the range $10 \mathrm{MPa}-150 \mathrm{MPa}$. Oxygen partial pressures were varied between $10^{-5} \mathrm{~atm}$. and air. The steady state creep rate seems to depend on the concentration of oxygen vacancies $\mathrm{V}_{\mathrm{o}}^{*}$, in agreement with an oxygen diffusion controlled creep mechanism.
\end{abstract}

1. Introduction. - High temperature steady state creep is generally diffusion controlled. In oxides, it is accepted that the creep rate is related to the diffusion coefficient of the slowest species. However no experimental proof has been well established [1, 2]. Nonstoichiometric oxides provide good systems for studying the relation between diffusion and creep [2]. In a previous note, we have suggested that the creep rate $\dot{\varepsilon}_{\mathrm{S}}$ of $\mathrm{NiO}$ single crystals is controlled by oxygen diffusion between $950^{\circ} \mathrm{C}$ and $1200^{\circ} \mathrm{C}$ in air [3]. Activation energies for creep [3] and diffusion [4] have been found to be very similar. We have then extended our measurements to higher temperature $\left(T \lesssim 1500^{\circ} \mathrm{C}\right)\left(1500^{\circ} \mathrm{C}=0.8 \mathrm{Tm}\right)$ and various oxygen pressure $\left(10^{-5}\right.$ atm. $<P_{\mathrm{O}_{2}}<0.21$ atm.; $\left.1 \mathrm{~atm} . \simeq 10^{-5} \mathrm{~Pa}\right)$. The experimental techniques and single crystals are the same as those used in [3] and [4]. The total impurity content (10-100 ppm) is smaller than the departure from stoichiometry $\left(10^{-4}\right.$ to $10^{-3}$ at $\left.1500^{\circ} \mathrm{C}\right)$. The law which describes the steady state creep is written $[1,5]$ :

$$
\dot{\varepsilon}_{\mathrm{S}}=A \sigma^{n} P_{\mathrm{O}_{2}}^{m} \exp -\frac{Q}{k T}
$$

$\left({ }^{*}\right)$ Part of the thesis of J.C.C., to be submitted.
The aim of the work is to determine the stress exponent $n$, the oxygen pressure exponent $m$ and the creep activation energy $Q$. For this we made stress, $P_{\mathrm{O}_{2}}$ or temperature changes and compared $\dot{\varepsilon}_{\mathrm{S}}$ values before and after the changes [1]. Care must be taken to ensure that the specimen has reached thermodynamic equilibrium after $P_{\mathrm{O}_{2}}$ or temperature change [5]. Annealing duration before resuming creep is determined in $\mathrm{NiO}$ by nickel vacancy diffusivities, i.e. chemical diffusion $[6,7]$. If we use the smallest diffusion coefficient $\tilde{D}[6]$, we find that $\sqrt{\tilde{D} t}=0.2 \mathrm{~cm}$ for annealing duration of 28 hours, 5.6 hours and 1.4 hour at $1100{ }^{\circ} \mathrm{C}, 1300^{\circ} \mathrm{C}$ and $1500^{\circ} \mathrm{C}$ respectively (specimen size : $2 \times 2 \times 5 \mathrm{~mm}^{3}$ ). Long enough annealing has been used to ensure that new equilibrium nonstoichiometry has been reached in the whole specimen; shorter duration can be used, because the diffusion is probably accelerated, at low temperature, by the large amount of dislocations due to plastic deformation. Annealing durations between $1 \mathrm{~h}$ and $18 \mathrm{~h}$ have been used, depending on temperature creep test, with no influence on $m$ and $Q$ values. Very long annealing does not improve the experiment because it leads to large dislocation recovery, followed by a transient, when resuming creep, which decreases the accuracy of the $n, m$ or $Q$ determination [5]. 
2. Results. - Fourteen $\mathrm{NiO}$ single crystals have been strained up to $\varepsilon \sim 0.6$ with $\sigma$ parallel to $\langle 100\rangle$. Among then, one was doped with $300 \mathrm{ppm} \mathrm{Cr}$; $n, m$ and $Q$ values have been extracted from steady state creep by 20 stress changes, 35 temperature changes and 30 oxygen pressure changes. The stress exponent $n$ decreases from 11.5 at $1150^{\circ} \mathrm{C}$ to 8.5 at $1350{ }^{\circ} \mathrm{C}$ and $6.8( \pm 1)$ at $1500^{\circ} \mathrm{C}$. This shows that, for an accurate description of results, the power creep law should be replaced by an exponential law, in particular at low temperature and high stress [1]. Values for $m$ and $Q$ are shown in figure 1. The accuracy for $m$ values is not better than \pm 0.05 and for $Q$ values $\pm 1 \mathrm{eV}$. More experiments would be necessary to decrease the scatter of experimental results. However, it can be seen (Fig. 1) that the minimum value for $Q$ is around $5.2 \mathrm{eV}$ [3] with higher values at higher temperature and lower $P_{\mathrm{O}_{2}}$. The $m$ values decrease from $m \simeq 0$ to $m \simeq-0.1$ (Fig. 1).

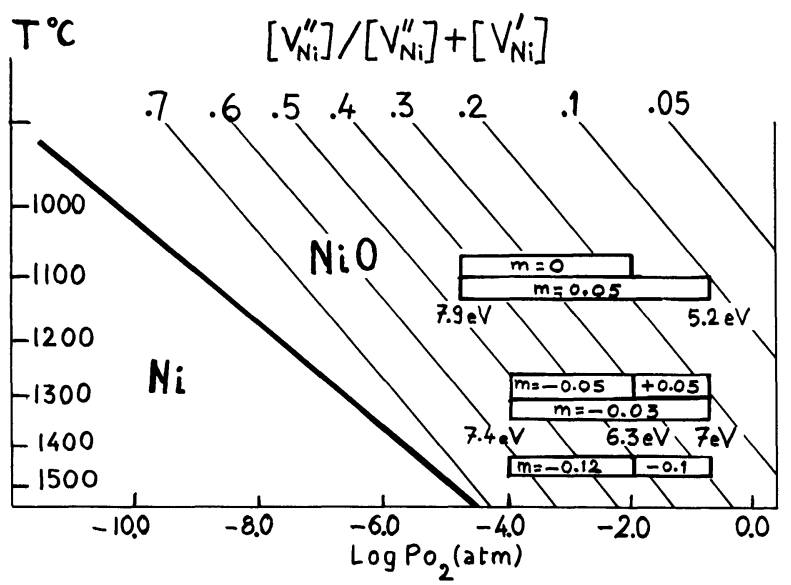

Fig. 1. - Stability range of $\mathrm{NiO}$ showing iso-concentration lines for $\mathrm{V}_{\mathrm{Ni}}^{\prime}$ and $\mathrm{V}_{\mathrm{Ni}}^{\prime \prime}$ as determined by [6]. Activation energies (eV) and $P_{\mathrm{O}_{2}}$ exponent $m$ for creep are shown for $T$ and $P_{\mathrm{O}_{2}}$ creep conditions ; $m$ values are shown in rectangles showing the $P_{\mathrm{O}_{2}}$ change used for their determination.

3. Discussion. - Nonstoichiometry has been explained in $\mathrm{NiO}$ by the presence of large amounts of nickel vacancies $\mathrm{V}_{\mathrm{Ni}}^{\prime}$ and $\mathrm{V}_{\mathrm{Ni}}^{\prime \prime}[6]$. Singly charged vacancy concentration $\left[\mathrm{V}_{\mathrm{Ni}}^{\prime}\right]$ is high at low temperature and high $P_{\mathrm{O}_{2}}$ and $\left[\mathrm{V}_{\mathrm{Ni}}^{\prime \prime}\right]$ is high at high temperature and low $P_{\mathrm{O}_{2}}$ (Fig. 1) [6]. If we accept the likely assumption that steady state creep is controlled by the diffusion of oxygen [1,2], we can explain the variation of $\dot{\varepsilon}_{\mathrm{S}}$ with $P_{\mathrm{O}_{2}}$ and determine the nature of the point defect $\mathrm{X}$ through which oxygen diffusion occurs.
Following a procedure previously developed [5], we deduced eq. (1) from :

$$
\dot{\varepsilon}_{\mathrm{S}}=B D_{\mathrm{O}} \sigma^{n}
$$

where $D_{\mathrm{O}}$ is the diffusion coefficient for oxygen :

$$
D_{\mathrm{O}}=[\mathrm{X}] D_{\mathrm{X}} f_{\mathrm{X}}
$$

$[\mathrm{X}]$ : concentration of defect allowing oxygen diffusion i.e. either oxygen vacancy $\mathrm{V}_{\mathrm{O}}$ or oxygen interstitial $\mathrm{O}_{\mathrm{i}}$

$D_{\mathbf{X}}$ : diffusion coefficient of $\mathrm{X}$

$f_{\mathrm{X}}$ : correlation factor taken constant.

The $P_{\mathrm{O}_{2}}$ exponent $m$ in eq. (1) is the same as that in the equation giving [X]. We can calculate it with the help of the Kröger-Vink formalism [8].

Results of such systematic calculations are summarized in [8], p. 358 for pure and doped binary oxides. For $\mathrm{NiO}$ in the intrinsic state, the results for 10 cases are shown in the table I.

Creep experiments give $m$ values that are close to zero or negative. This indicates that oxygen diffuses through vacancies. Moreover, $m$ values tend to be zero when $\mathrm{V}_{\mathrm{Ni}}^{\prime}$ is dominant (Fig. 1) and -0.1 when $\mathrm{V}_{\mathrm{Ni}}^{\prime \prime}$ is dominant (Fig. 1). This strongly suggests that the point defect in the oxygen sublattice which explain diffusion controlled creep is $\mathrm{V}_{\mathrm{O}}^{*}$. This result is in agreement with that suggested from an entropy analysis of oxygen self-diffusion [4].

The variation of $\mathrm{V}_{\mathrm{O}}^{*}$ concentration with $P_{\mathrm{O}_{2}}$ and $T$ can be calculated when $\mathrm{V}_{\mathrm{N} i}^{\prime}$ or $\mathrm{V}_{\mathrm{Ni}}^{\prime \prime}$ are dominant. The formation equation of $\mathrm{V}_{\mathrm{Ni}}^{\prime}$ is :

$$
\frac{1}{2} \mathrm{O}_{2} \rightleftarrows \mathrm{O}_{0}+\mathrm{V}_{\mathrm{Ni}}^{\prime}+\mathrm{h}\left(\Delta G_{4}\right)
$$

giving for hole $\mathrm{h}$ and vacancy concentration :

$$
[\mathrm{h}]=\left[\mathrm{V}_{\mathrm{Ni}}^{\prime}\right]=P_{\mathrm{O}_{2}}^{0.25} \exp -\frac{\Delta G_{4}}{2 k T} .
$$

We can write for the formation equation of $V_{0}^{*}$ :

$$
2 \mathrm{~h}+\mathrm{O}_{0} \rightleftarrows \mathrm{V}_{\mathrm{o}}^{*}+\frac{1}{2} \mathrm{O}_{2}\left(\Delta G_{6}\right)
$$

giving with the help of eq. (5) :

$$
\left[\mathrm{V}_{\mathrm{o}}^{*}\right]=\exp -\frac{\Delta G_{4}+\Delta G_{6}}{k T} .
$$

As shown in the table $\mathrm{I}$, when $\mathrm{V}_{\mathrm{Ni}}^{\prime}$ and $\mathrm{V}_{\mathrm{O}}^{*}$ are the dominant defects in $\mathrm{Ni}$ and $\mathrm{O}$ sublattices, the concentration of $V_{O}^{*}$ is independent of oxygen pressure.

Table I. $-P_{\mathrm{O}_{2}}$ exponent $m$ for the concentration $[\mathrm{X}]$ of point defect $\mathrm{X}$ in the oxygen sublattice for various combinations of oxygen and nickel defects (after [4]).

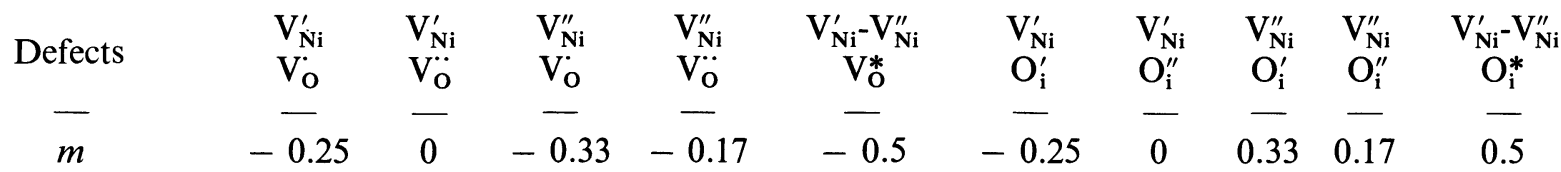


When $\mathrm{V}_{\mathrm{N} \mathbf{i}}^{\prime \prime}$ is dominant we write :

$$
\begin{gathered}
\frac{1}{2} \mathrm{O}_{2} \rightleftarrows \mathrm{O}_{0}+\mathrm{V}_{\mathrm{Ni}}^{\prime \prime}+2 \mathrm{~h}\left(\Delta G_{8}\right) \\
{[\mathrm{h}]=2\left[\mathrm{~V}_{\mathrm{Ni}}^{\prime \prime}\right]=2^{1 / 3} P_{\mathrm{O}_{2}}^{0.17} \exp -\frac{\Delta G_{8}}{3 k T} .}
\end{gathered}
$$

Then from reaction (6) and (8) :

$$
\left[\mathrm{V}_{\mathrm{o}}^{*}\right]=2^{2 / 3} P_{\mathrm{O}_{2}}^{-0.17} \exp -\frac{\Delta G_{6}+(2 / 3) \Delta G_{8}}{k T} .
$$

A comparison of eqs. (7) and (10) shows that the activation energy for oxygen diffusion controlled creep is different depending on whether $\mathrm{V}_{\mathbf{N i}}^{\prime}$ or $\mathrm{V}_{\mathbf{N i}}^{\prime \prime}$ is the dominant point defect. The difference in diffusion activation energy is : $\frac{2}{3} \Delta G_{8}-\Delta G_{4}$.

We can estimate its value from electrical conductivity $\sigma_{\mathrm{e}}$ measurements [6] :

$$
\sigma_{\mathrm{e}}=e \mu[\mathrm{h}]
$$

where $\mu$ is the hole mobility. When $\mathrm{V}_{\mathrm{Ni}}^{\prime}$ is the dominant point defect, the activation enthalpy for $\sigma_{\mathrm{e}}$ can be deduced from (5) and (11) :

$$
\Delta H_{\sigma}=-k \frac{\partial \ln \sigma_{\mathrm{e}}}{\partial 1 / T}=\frac{\Delta G_{4}}{2}+\Delta H m
$$

where $\Delta H m$ is the activation enthalpy for hole mobility.

Experimental determination gives [6] :

$$
\Delta H_{\sigma} \simeq 0.9 \mathrm{eV} .
$$

When $\mathrm{V}_{\mathrm{Ni}}^{\prime \prime}$ is the dominant point defect one finds from (9) and (11) [6] :

$$
\Delta H_{\sigma}=\frac{\Delta G_{8}}{3}+\Delta H m \simeq 1.2 \mathrm{eV} .
$$

Eqs. (12), (13) and (14) allow an estimate to be made of the maximum variation in diffusion activation enthalpy :

$$
\frac{2}{3} \Delta G_{8}-\Delta G_{4} \simeq 0.6 \mathrm{eV} .
$$

When $\mathrm{V}_{\mathrm{Ni}}^{\prime \prime}$ is the dominant point defect (high $T$, low $P_{\mathrm{O}_{2}}$, Fig. 1), the activation enthalpy for oxygen diffusion exceeds by $0.6 \mathrm{eV}$ that corresponding to $\mathrm{V}_{\mathrm{Ni}}^{\prime}$. A value of $5.6 \pm 0.5 \mathrm{eV}$ has been found for oxygen self-diffusion [4]. For creep, values are between $5.2 \pm 1 \mathrm{eV}$ and $7.9 \pm 1 \mathrm{eV}$ (Fig. 1). In both cases, results are rather inaccurate, but they are in qualitative agreement. In order to have a full understanding of activation process, one must take into account the following facts : (i) The Arrhenius plot for oxygen self-diffusion in air has been analysed as a straight line [4]. There might be some curvature at high temperature giving larger activation energies as suggested from point defect analysis.

(ii) $Q$ has been determined with the help of eq. (1) which gives large $n$ values. This means that $Q$ is better written as $Q_{0}-V \sigma$ [1], where $Q_{0}$ must be compared to diffusion data. This would explain values for creep smaller than for diffusion.

(iii) Eq. (2) is based on the assumption that creep is diffusion controlled. Dislocation point defect interaction jog formation and mobility energies might influence the creep rate and give activation enthalpies larger than diffusion enthalpies [1].

Oxygen pressure dependence is then a better way for checking the models.

Such an experiment has been performed on a $300 \mathrm{ppm}$ chromium doped specimen. Calculations can be performed with one of the neutrality equations :

$$
\left[\mathrm{V}_{\mathbf{N i}}^{\prime}\right]=\left[\mathrm{Cr}_{\mathbf{N i}}^{\cdot}\right]
$$

or

$$
2\left[\mathrm{~V}_{\mathrm{Ni}}^{\prime \prime}\right]=\left[\mathrm{Cr}_{\mathrm{Ni}}^{\cdot}\right] .
$$

For $\mathrm{V}_{\mathrm{o}}^{*}, m$ values of 0.5 with eq. (16) and $m=0$ with eq. (17) can be deduced ([8], p. 359). Creep experiments give a $m$ value of 0.35 (two measurements) between air and $P_{\mathrm{O}_{2}}=1 \%$ atm. at $1120{ }^{\circ} \mathrm{C}$ and $m \simeq-0.01$ (two measurements) between $P_{\mathrm{O}_{2}}=1 \%$ atm. and $2 \times 10^{-5} \mathrm{~atm}$. at $1320^{\circ} \mathrm{C}$. If the diagram of the figure 1 is still valid for doped $\mathrm{NiO}$, the creep conditions correspond respectively to dominant $\mathrm{V}_{\mathrm{Ni}}^{\prime}$ and $\mathbf{V}_{\mathbf{N}}^{\prime}$. Experimental values are in fair agreement with predictions from calculations assuming, again $\mathrm{V}_{\mathrm{O}}^{*}$ as a dominant defect in the oxygen sublattice.

4. Conclusion. - In a previous study of this type, high temperature creep of $\mathrm{Cu}_{2} \mathrm{O}$ has been explained in terms of oxygen self-diffusion and suggested an interstitial point defect in the oxygen sublattice [5]. This result is in fairly good agreement with more recently performed [9] oxygen diffusion measurements. The situation in $\mathrm{NiO}$ is more complicated because nonstoichiometry is described by a mixture of $\mathrm{V}_{\mathrm{Ni}}^{\prime}$ and $\mathrm{V}_{\mathrm{Ni}}^{\prime \prime}$. However, creep experiments lead to the conclusion that $\mathrm{V}_{\mathbf{O}}^{*}$ is the dominant point defect in the oxygen sublattice.

Acknowledgments. - The authors wish to acknowledge Dr C. Monty for helpful discussions on point defect models and the French Ministery of Foreign Affairs for financial assistance. 


\section{References}

[1] Bretheau, T., Castaing, J., Rabier, J. et Veyssière, P., $A d v$. Phys., to be published.

[2] Mitchell, T. E., Hobbs, L. W., Heuer, A. H., Castaing, J., CAdoz, J., Philibert, J., Acta Metall., to be published.

[3] Cabrera-Cano, J., Dominguez-Rodriguez, A., Marques, R. and Castaing, J., J. Physique Lett. 39 (1978) L-451.

[4] Dubois, C., Thèse, Université Paris 11, Orsay.

[5] Bretheau, T., Marhic, C., Spendel, M. and Castaing, J., Philos. Mag. 35 (1977) 1473.
[6] Farhi, R. and Petot-Ervas, G., J. Phys. Chem. Solids 39 (1978) 1169 and 1175.

[7] Nowotny, J. and Sadowski, A., J. Am. Ceram. Soc. 62 (1979) 24.

[8] Monty, C., Défauts ponctuels dans les solides (Les Editions de Physique, Orsay, France), Confolant 1977, Ch. XII.

[9] Perinet, F., Barbezat, S., Monty, C., Conf. on Lattice defects in ionic crystals, Canterbury Sept. 1979, J. Physique, to be published. 